\title{
Saint Vincent and the Grenadines
}

National Cancer Institute

\section{Source}

National Cancer Institute. Saint Vincent and the Grenadines. NCI Thesaurus. Code

C17114.

A group of islands between the Caribbean Sea and the North Atlantic Ocean, south of Saint Lucia and north of Granada. 